\title{
Analysis of psoriasis-relevant gene expression and exon usage alterations after silencing of SR-rich splicing regulators
}

\author{
Eszter Szlavicz ${ }^{1,2}$ (D) | Peter Olah ${ }^{2,3}$ | Kornélia Szabo ${ }^{1,4}$ | Franco Pagani ${ }^{5}$ | \\ Zsuzsanna Bata-Csorgo $^{1,4}$ | Lajos Kemeny ${ }^{1,4}$ | Márta Szell ${ }^{4,6}$
}

${ }^{1}$ Faculty of Medicine, Department of Dermatology and Allergology, University of Szeged, Szeged, Hungary

${ }^{2}$ Faculty of Medicine, Department of Dermatology, Venereology and Oncodermatology, University of Pécs, Pécs, Hungary

${ }^{3}$ Department of Dermatology, University Hospital Düsseldorf, Düsseldorf, Germany

${ }^{4}$ MTA-SZTE Dermatological Research Group, University of Szeged, Szeged, Hungary

${ }^{5}$ International Centre for Genetic Engineering and Biotechnology, Trieste, Italy

${ }^{6}$ Faculty of Medicine, Department of Medical Genetics, University of Szeged, Szeged, Hungary

\section{Correspondence}

Eszter Szlavicz, Department of Dermatology and Allergology, University of Szeged,

Szeged, Hungary.

Email: szlavicz.eszter@gmail.com

Funding information

Országos Tudományos Kutatási

Alapprogramok, Grant/Award Number: 5K321 and K105985; Gazdaságfejlesztési és Innovációs Operatív Program, Grant/Award Number: GINOP-2.2.1-15-2016-00007 and GINOP-2.3.2-15-2016-00015; Országos Tudományos Kutatási Alapprogramok, Grant/Award Number: 5 K321 and K105985; Gazdaságfejlesztési és Innovációs Operatív Program, Grant/Award Number: GINOP-2.2.1-15-2016-00007 and GINOP-2.3.2-15-2016-00015

\begin{abstract}
In our recent CDNA microarray experiment, three SR-rich splicing factors-SFRS18, PPIG and LUC7L3-were shown to exert altered responsiveness upon T-lymphokine stimulation of psoriatic non-involved and healthy epidermis samples. We have also demonstrated that double silencing LUC7L3 and SFRS18 efficiently decreased production of the psoriasis-associated EDA+ fibronectin isoform. These findings prompted the further investigation of signalling pathways affected by LUC7L3 and SFRS18. To detect gene expression and splicing pattern alterations upon double silencing of LUC7L3 and SFRS18 in an HPV-immortalised keratinocyte cell culture, paired-end RNA sequencing was carried out. Marked changes in exon usage were revealed, in contrast to the modest alterations detected in gene expression, providing a closer delineation of the potential targets of the examined splicing factors. The most prominent gene expression change was detected for IFI6, an interferoninducible gene highly expressed in psoriasis. Interacting partners of IFI6 and certain psoriasis-associated transcripts also exhibited significantly increased expression upon silencing. In addition to elevated abundance of the EDA+ fibronectin interactor ITGA5, we confirmed decreased EDA domain inclusion, which agrees well with our prior experimental data. Furthermore, differential exon usage was established for the transcription element CREB1, along with HERC 6 and CUL1, which are implicated in ubiquitination. Although immortalised keratinocytes express low levels of TINCR, a long non-coding RNA involved in terminal differentiation of keratinocytes, splicing alterations were successfully demonstrated for this RNA as well. We believe that the targeted investigation of mRNA maturation disturbances may help us gain deeper insight into the molecular pathogenesis of psoriasis.
\end{abstract}

KEYWORDS

antiviral immunity, inflammation, mRNA maturation, non-coding RNAs, RNA-Sequencing

\section{1 | INTRODUCTION}

Psoriasis is one of the most common chronic inflammatory skin disorders, affecting $2 \%-3 \%$ of the Caucasian population with

Eszter Szlavicz and Peter Olah equally contributed to this study unquestionable negative impacts on quality of life. Characterisation is complicated by the multifactorial origin of the disease, as the interplay of genetic and environmental factors has great influence on the formation of psoriatic lesions. It is well established that innate and adaptive immunological processes both interact in disease pathogenesis. ${ }^{[1-3]}$ Recent findings indicate that activation 
of plasmacytoid dendritic cells could be a determinant step in the initiation phase of psoriasis, which is triggered by the complexes of cathelicidin (LL37) and the self-DNA/RNA of stressed keratinocytes. ${ }^{[3-6]}$ This step is followed by the release of type I interferons, as well as the consecutive production of other inflammatory mediators, such as IL-1 $\beta$, IL- 6 and TNF $\alpha$, which are activators of myeloid dermal dendritic cells. ${ }^{[3,6,7]}$ This cell type is an important source of IL-12 and IL-23, which are cytokine products that stimulate multiple T-cell lineages implicated in further pathogenic steps, including Th1, Th17 and Th22 lymphocytes. ${ }^{[1,3,7,8]}$ Different stages of the disorder are characterised by unique cytokine profiles: whereas the primary phase is dominated by Th1 cells, the propagation of the disorder entails increasing involvement of the Th17 pathway. ${ }^{[3,9]}$ Besides the above-mentioned molecular pathways, we should also mention the involvement of further contributors, including the regulation of antimicrobial defense pathways, lipid metabolism and fatty acid metabolism, Wnt-signalling pathway and IL10 family cytokines, which are implicated to play crucial roles in disease development. ${ }^{[10-18]}$ Related members of the IL-36 family, including IL37 and IL38, have also been investigated in detail in the context of psoriasis. ${ }^{[17-19]}$ Despite the wealth of data, our knowledge regarding the complexity of molecular mechanisms in psoriasis is still incomplete, and further experiments are needed for the detailed description of the molecular background of this inflammatory skin disorder.

In recent years, large-scale gene expression studies have become more accessible and several studies have been conducted to describe gene expression differences in healthy, psoriatic non-involved and involved epidermis. ${ }^{[13,20-22]}$ The majority of these studies, however, investigated steady-state gene expression levels of various patientderived samples. In contrast to previous works, we recently investigated T-lymphokine-induced gene expression changes between healthy and psoriatic non-involved epidermis in a cDNA microarray experiment. ${ }^{[23]}$ In our experimental setup, organotypic skin cultures were generated, and half of the samples, both healthy and noninvolved epidermis, were treated with a T-lymphokine mixture containing IFN- $\gamma$, IL3 and GM-CSF. This T-lymphokine combination has been shown to facilitate the proliferation of keratinocyte precursors in psoriatic non-involved epidermis; thus, it is likely that these cytokines are important participants of early disorder development. ${ }^{[24]}$

When comparing T-lymphokine-induced gene expression between healthy and psoriatic epidermis, three SR-rich splicing factors-arginine/serine-rich 18 (SFRS18), peptidyl-prolyl cis-trans isomerase G (PPIG) and luc-7 like protein 3 (LUC7L3)-were found to be differentially regulated in healthy and non-involved psoriatic keratinocytes. SR proteins, which contain a serine/argininerich domain and at least one domain for RNA binding, are the trans-regulators of mRNA maturation. Usually-although not exclusively-they bind to enhancer elements and promote exon inclusion. ${ }^{[25,26]}$ The finding is notable, as only a few articles concerning psoriasis and mRNA maturation have been published: we and others have shown that, compared to the healthy samples, the fibronectin isoform containing extra domain A (EDA+ fibronectin) is overexpressed in psoriatic non-involved epidermis and modifies the response of keratinocytes to T-lymphokine stimuli. ${ }^{[27-29]}$ The EDA domain of fibronectin belongs to the type III repetitive modules and is encoded by exon 33 of the fibronectin (FN1) gene. ${ }^{[30-33]}$ In subsequent experiments, we successfully verified that the aforementioned splicing regulators are able to facilitate EDA domain inclusion. Data mining using publicly available interaction databases also supported the credibility of the interaction of LUC7L3 and SFRS18 splicing regulators. ${ }^{[34]}$ These data suggest that these splicing factors indeed contribute to disease pathogenesis and their effect is-at least partially-mediated by the regulation of psoriasisassociated EDA+ fibronectin.

In this study, we aim to determine additional molecular pathways influenced by the SR-rich splicing regulators, LUC7L3 and SFRS18, as the combined effects of these two genes proved to be the most potent in prior experiments. ${ }^{[34]}$ Global transcriptome analysis was performed using pair-end RNA-Sequencing (RNA-Seq) to define gene expression changes and differential exon usage in human papillomavirus (HPV)-immortalised keratinocytes.

\section{2 | MATERIALS AND METHODS}

\section{1 | Culturing of HPV-KER cells}

As we described previously, HPV-KER cell line was prepared by immortalisation with HPV E6 oncogene. ${ }^{[35]}$ HPV-immortalised keratinocytes were grown in $75 \mathrm{~cm}^{2}$ cell culture flasks at $37^{\circ} \mathrm{C}$ in a humidified atmosphere containing $5 \% \mathrm{CO}_{2}$. For the maintenance of the cultures, keratinocyte serum-free medium was used (Gibco ${ }^{\circledR}$ Keratinocyte SFM Kit; Life Technologies, Copenhagen, Denmark), supplemented with 1\% L-glutamine (PAA, Pasching, Austria) and $1 \%$ antibiotic/antimycotic solution (PAA). The medium was changed every 2 days.

\section{2 | Gene-specific silencing}

HPV-KER cells were transiently transfected with gene-specific siRNAs at approximately 70\% confluency. Transfection medium and reagents were obtained from Santa Cruz Biotechnology (Dallas, TX, USA). In our siRNA-mediated silencing experiments, scrambled and gene-specific LUC7L3 and SFRS18 siRNA duplexes were used. The most effective silencing results were obtained in serum-free culture medium without additive and supplements. Real-time RT-PCR was used to confirm the effectiveness of silencing. Quality control of samples submitted to RNA-Seq was carried out by Bioanalyzer (Agilent, Santa Clara, CA, USA), and the measurements indicated excellent RNA quality (RIN: 10).

\section{3 | Sequencing}

Libraries were prepared with cDNA using the Illumina-compatible ScriptSeq RNA-Seq Library Preparation Kit (Epicenter) for $2 \times 100 \mathrm{bp}$ paired-end library construction, for two technical 
replicates per condition (silenced and control). Sequencing was carried out on the Illumina HiScan SQ platform, resulting in an average depth of $\sim 35$ million raw reads per sample. Library preparation and sequencing were carried out in the Center for Clinical Genomics and Personalized Medicine, University of Debrecen.

\section{4 | Statistical analysis and bioinformatics}

Raw reads in FASTQ format were submitted to quality control using FASTQC, followed by quality and adapter trimming using the fastx toolkit. Filtered reads were mapped to the $\mathrm{Hg} 19$ human reference with the STAR aligner, using parameters optimised for splice-site discovery. ${ }^{[36]}$ In silico contaminant screening was also carried out, and ambiguously mapping reads were discarded from further analysis. Potential fusion transcripts were predicted by TopHat2 using the fusion-search algorithm. ${ }^{[3]}$ Following mapping, transcript assembly and annotation were carried out using Cufflinks, and read counts were summarised at the gene and exon levels using htseqcount. ${ }^{[38,39]}$ Count data were then processed using the DESeq and DEXSeq packages to quantify differential gene expression and differential exon usage, respectively. ${ }^{[40]}$ Exons with a coverage $<5$ reads were discarded from the analysis. Functional annotation of differentially expressed genes was carried out using Gene Ontology (GO) enrichment, and extensive comparisons with previous literature-based gene sets and data visualisation were carried out in $\mathrm{R}$ version 3.0.1, and Cytoscape.

\section{5 | Real-time RT-PCR}

Using the iScript TM cDNA Synthesis kit (\#1708891, Bio-Rad, Hercules, CA), 1 mg total RNA purified from HPV-KER cells was reverse transcribed. Subsequently, real-time RT-PCR was carried out using custom primer sets and the Universal Probe Library (Roche, Basel, Switzerland) with an iQ Supermix (\#1708862, Bio-Rad, Hercules, CA) to quantify transcript abundance. Relative gene expression data were calculated by the $\Delta \Delta \mathrm{Ct}$ method, normalising the expression to the $18 \mathrm{~S}$ ribosomal RNA.

\section{6 | PCR}

Samples were collected from the siRNA-silenced HPV-KER cell cultures, and total RNA was isolated using the TRIzol ${ }^{\circledR}$ Reagent (Invitrogen Corp., Carlsbad, CA, USA), according to the instructions of the manual. cDNA synthesis was performed with the iScript cDNA Synthesis Kit (Bio-Rad Laboratories, Hercules, CA, USA) from $1 \mu \mathrm{g}$ total RNA. To amplify a 847-bp product from EDA- fibronectin and a 1221-bp product from EDA+ fibronectin, specific primers were used with PCR conditions summarised in Szell et al (2004). Semiquantitative analysis of the differentially spliced fibronectin isoforms is also described in the referred paper. Amplification products $(10 \mu \mathrm{L})$ were size fractionated on a $1 \%$ agarose gel at $90 \mathrm{~V}$. Image acquisition and analysis were carried out on a Bio-Rad GelDoc XR densitometer.

\section{3 | RESULTS}

Immortalised HPV-KER cells in which both the LUC7L3 and SFRS18 splicing regulators were silenced were subjected to RNA-Seq profiling. Silencing efficiencies, determined by qPCR prior to sequencing, were between $\sim 70 \%-80 \%$ (Figure S1). Following read mapping to reference Hg19, de novo transcript assembly was performed to identify the potentially novel transcripts and isoforms in the HPV-KER cell line, as well as to provide accurate exon-level annotation for downstream analyses. To assess the alterations caused by the dual silencing of the splicing factors, differential expression and differential exon usage metrics were generated, allowing the complexity and possible errors introduced by isoform reconstruction methods to be circumvented. ${ }^{[41,42]}$

\section{1 | Differential gene expression}

As expected from the experimental model, combined silencing of the LUC7L3 and SFRS18 splicing factors resulted in moderate changes in gene expression (Figure S2), accompanied by extensive disturbances in exon inclusion and exclusion rates. As a result, 35 protein-coding genes were identified as differentially expressed (logFC $>0.5$, FDR < 0.05), with IFI6 and MX1, ISG15 and KRT6A mRNAs showing the most robust fold-changes. Notably, the majority of these regulated genes share functions related to type I interferon signalling based on enrichment analysis. The most significant enriched GO terms were cellular response to type I interferon, cellular response to cytokine stimulus (GO:0071345) and regulation of viral genome replication (GO:0045069); these functions were also identified in the functional interaction network based on the Reactome and GeneMania databases (Figure 1A). Independent qPCR validation of IFI6 expression indicated up to fourfold changes, which agrees well with our high-throughput results (Figure 1B).

\section{2 | Differential exon usage}

Differential exon usage was measured for the assembled transcript models, and detected in 224 exons of 217 genes at $\operatorname{logFC}>0.5$, FDR $<0.1$, corresponding to $P$-value $<7 \times 10^{-4}$. It is notable that differential usage of multiple exons per gene was detected for a considerable number of genes throughout the dataset, possibly indicating fine-tuned changes induced by silencing. Differential exon usage was detected in several non-coding RNAs, whereas functional network analysis of the most significant genes indicted an extensive co-expression background, suggesting overlapping regulation at the transcriptional and post-transcriptional levels (Figure 2). Transcripts regulated with regard to splicing pattern alterations did not exhibit extensively shared molecular functions, in contrast to regulation detected at the gene expression level. Notably, mining of co-expression-level databases resulted in the identification of abundant relations between regulated genes, indicating their coordinated transcriptional regulation, and, as supported by our current dataset, possibly shared post-transcriptional processing events. The resulting complete functional network contained 172 genes, with only 4 


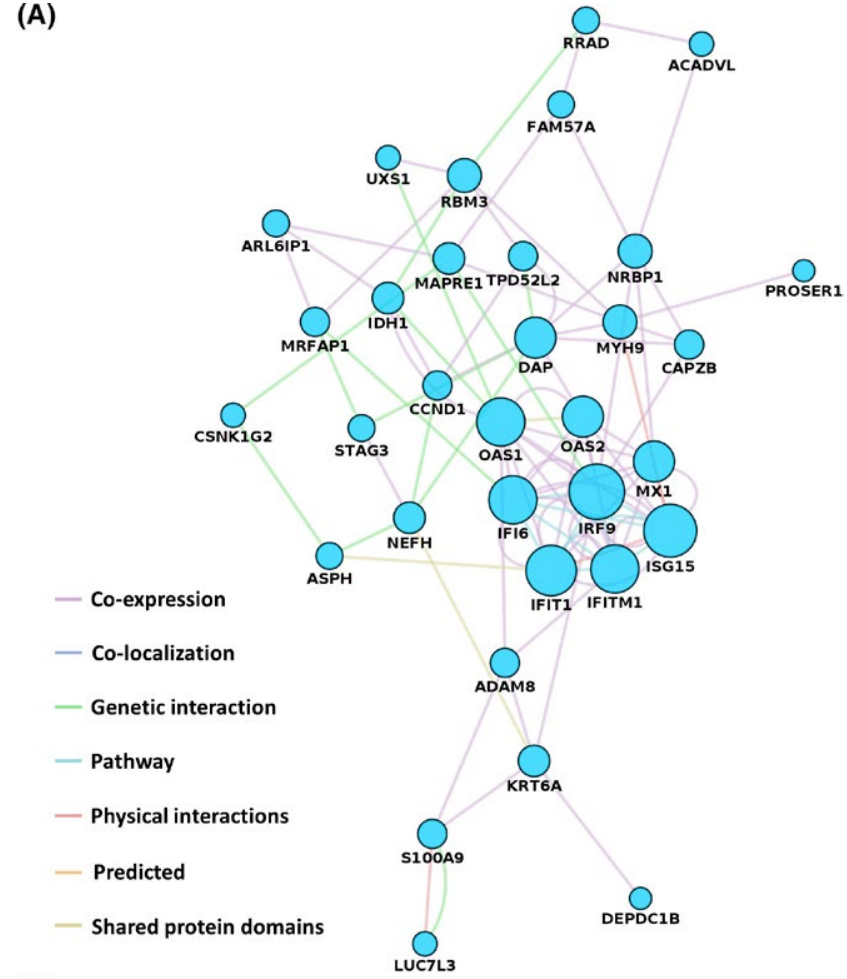

(B)

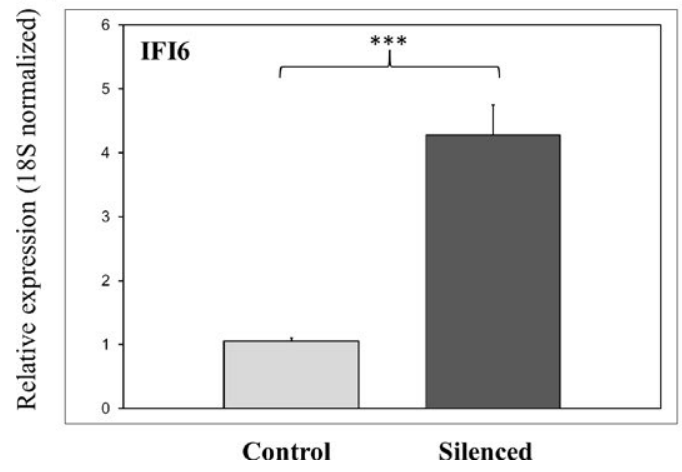

FIGURE 1 Functional network of significantly differentially expressed genes (log2FC > 0.5, FDR $<0.05)$ in response to dual silencing of LUC7L3 and SFRS18, with edges corresponding to GeneMania and Reactome annotation categories (A). qRT-PCR validation of IFI6 expression changes in siRNA-silenced samples; columns present the mean of three independent experiments. $P<.05$ was considered as statistically significant $(B) .{ }^{*} P<.05$; ${ }^{* *} P<.01 ;{ }^{* * *} P<.001$.

disconnected nodes, and an average node connectivity degree of 13.4. Most connecting edges corresponded to co-expression, followed by physical and genetic interactions. The core set of the most highly connected genes is presented in Figure 3.

Experimental validation of fibronectin exon usage was also carried out on the scrambled controls and siRNA-silenced samples of the RNA-Seq experiment. RT-PCR using exon-specific, junctionspanning primers for fibronectin transcripts, followed by visualisation with agarose gel electrophoresis, indicated significantly altered inclusion of exon 33 (encoding the EDA domain) and the decreased relative abundance of the EDA+ isoform (Figure 4).
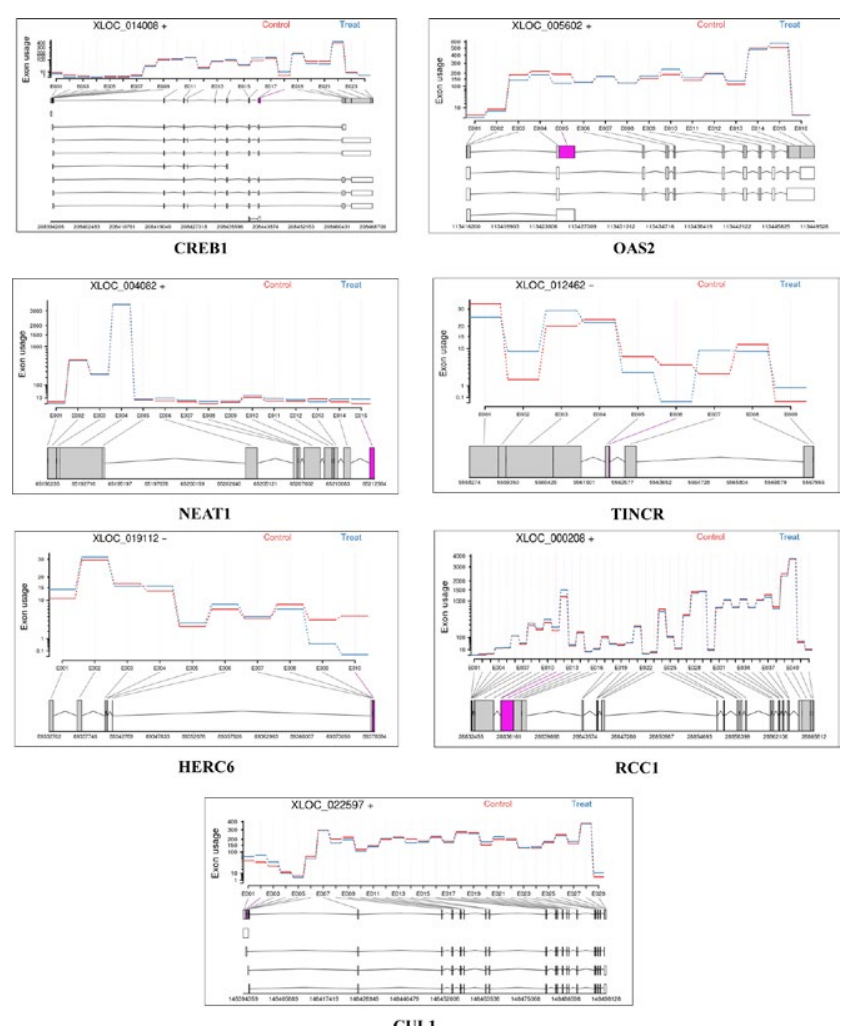

CULA

FIGURE 2 DEXSeq differential exon usage plots of selected transcripts showing significant alterations $(\log F C>0.5$, FDR $<0.1)$. Red: average exon usage frequency in control samples; blue: average exon usage frequency in treated samples; and pink: significantly differentially expressed exons. De novo assembled transcript diagrams depicted in bottom rows

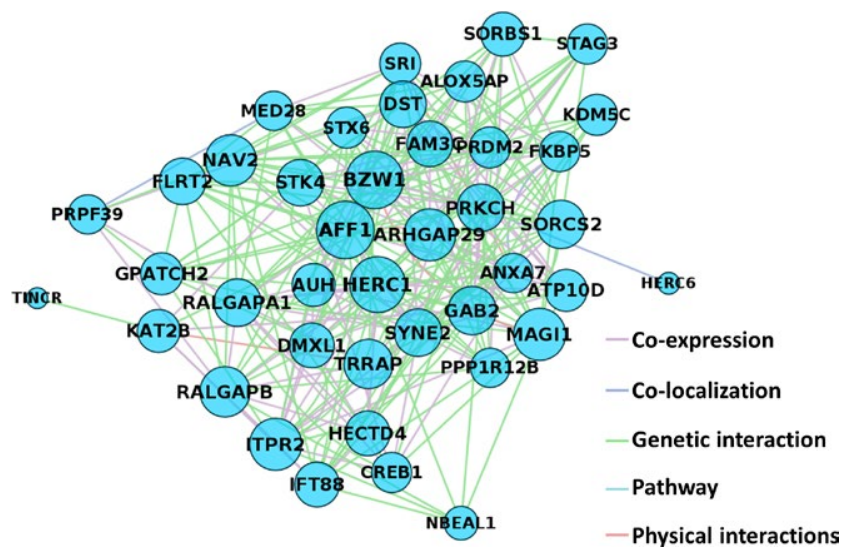

FIGURE 3 Subnetwork representation of a functional network constructed from genes exhibiting significant exon usage changes, with edge colour corresponding to GeneMania and Reactome annotation categories

\section{4 | DISCUSSION}

In recent years, next-generation sequencing-based gene expression profiling techniques, such as RNA-Seq, have revolutionised psoriasis research. RNA-Seq possesses a wider dynamic range compared to microarrays and permits the investigation of potentially novel 


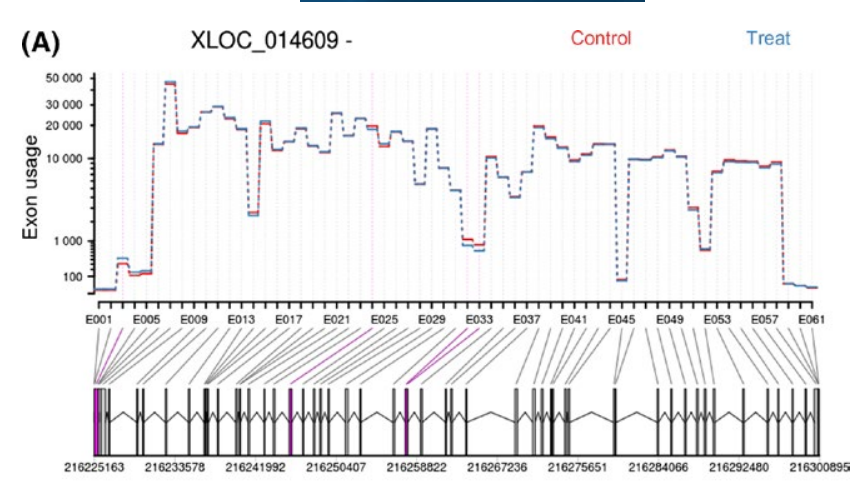

(B)

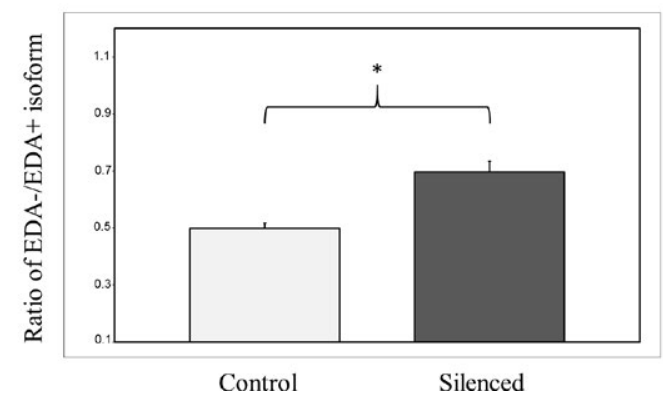

FIGURE 4 DEXSeq differential exon usage plot of fibronectin (FN1), showing the differential inclusion of exon 33, encoding the oncofetal EDA domain. Red indicates the average exon usage frequency in control samples and blue in silenced samples. Significantly differentially expressed exons are indicated in pink. (A) Independent qRT-PCR-based validation of differential exon usage, indicating abundance of alternative splicing variants in control (grey) and treated (black) samples in double replicates. Significance threshold: $P<.05$ (B)

transcripts, non-coding RNAs and different splicing isoforms. ${ }^{[43-47]}$ Nonetheless, only a few psoriasis studies to date address differential exon usage or altered expression of RNA isoforms. ${ }^{[17,45,47]}$

LUC7L3 and SFRS18 splicing factors have been selected based on the results of the aforementioned cDNA microarray experiment, where we identified genes showing T-lymphokine-induced differential expression among control and psoriatic non-involved epidermis. ${ }^{[23,34]}$ Products encoded by LUC7L3 and SFRS18 genes are both SR-rich splicing regulators. LUC7L3-which has a strong sequence similarity with yeast U1 snRNP component Luc7p-has also been shown to participate in the cisplatin-induced resistance of tumor cells. ${ }^{[48,49]}$ Another report suggests LUC7L3 protein binding to the CAMP-responsive element, and a recent article claimed antiviral property for this splicing regulator. ${ }^{[50,51]}$ Relatively few data are available for SFRS18. Zimowska and Lin et al reported interaction of the cell adhesion and splicing protein pinin (PNN) and SFRS18. ${ }^{[52,53]}$

The main purpose of the present study was to determine differential gene expression and exon usage upon altered expression of LUC7L3 and SFRS18. In agreement with our primary hypothesis, the extent of gene expression changes was relatively moderate; in contrast, several significant alterations in differential gene expression were induced by the siRNA transfection. Among these data, the most pronounced change was observed for IFI6 (also known as G1P3), an interferon-stimulated gene (ISG), which mediates anti-inflammatory, antiviral and antiproliferative effects of interferons. IFI6 is a member of the human ISG12 family, which also includes ISG12A (IFI27), ISG12B and ISG12C. In contrast to other ISG12 isoforms, IFI6 was demonstrated to possess an antiapoptotic feature. ${ }^{[54]}$ In addition to its involvement in cancer, biological function of IFI6 in psoriasis pathogenesis has also been reported. ${ }^{[4,55]}$ Based on the previous results of our research group, IFI6 might contribute to keratinocyte survival due to its antiapoptotic effect. Experimental data suggest elevated IFI6 gene expression both in the psoriatic noninvolved and involved epidermis as compared to the healthy samples. ${ }^{[5]}$ Gene expression changes of IFI6 have been successfully validated, exhibiting up to fourfold elevation in expression. In addition, we demonstrated increased levels of the ISG12 (IFI27) mRNA, also implicated in psoriasis. ${ }^{[56]}$ Thus, LUC7L3/SFRS18 might contribute to balancing proand antiapoptotic events.

Furthermore, several predicted interactors for IFI6 (https:// string-db.org/cgi/network.pl?taskld=Mq3bitC7×2Bp) exhibited significant upregulation in the silenced cells. Of these predicted genes, we detected OAS1, OAS2, IFIT1, IFIT3, ISG15 and MX1, all of which are related to antiviral immunity. ${ }^{[57,58]}$ The elevated expression of MX1, ISG15 and OAS2 in psoriatic skin samples has been verified in a previous experiment. ${ }^{[58]}$ In a recent RNA-Seq experiment, Raposo and his co-workers found that 16 antiviral genes-including ISG15-showed at least twofold elevation in psoriatic epidermis. ${ }^{[58]}$ OAS2 and another oligoadenylate synthetase, OAS3, have been shown to be elevated in psoriatic lesional skin in several previous transcriptome-wide studies. ${ }^{[17,45,59]}$ We have also demonstrated LUC7L3/SFRS18-regulated expression of KRT6A and S100A9, which are known innate immunity-related molecules. ${ }^{[60,61]}$

In contrast to our results for differential gene expression, our investigation of differential exon usage indicated more robust alterations. The extracellular matrix protein fibronectin is one of the most suitable models for studying splicing events. The presence of the EDA domain is associated with intrauterine development, wound healing and cancer pathogenesis. ${ }^{[32,33]}$ In addition, EDA+ fibronectin was demonstrated to be a putative factor modifying keratinocyte response to mitogenic signals. ${ }^{[28]}$ In our previous work, we verified that, similarly to other SR-rich proteins (such as SF2/ASF), LUC7L3, PPIG and SFRS18 also facilitate inclusion of the EDA domain. ${ }^{[11,62,63]}$ We were able to validate the significant changes of EDA+/EDA- fibronectin abundances in our present large-scale experiment as well. ${ }^{[34]}$ In addition to differential splicing of fibronectin, we also demonstrated the significant upregulation of ITGA5, a fibronectin receptor. Data in the literature demonstrate that the presence of the EDA domain alters the binding features of fibronectin and increases its affinity for ITGA5. ${ }^{[31,64,65]}$ Elevated levels of ITGA5 might be a compensatory mechanism against the decreased relative amount of EDA+ fibronectin.

LUC7L3, formerly designated CREAP-1, is characterised by its binding domain for the CAMP regulatory element. ${ }^{[50]}$ However, in addition to potential direct interaction with CRE, silencing of the splicing factors also alters the splicing pattern of CREB1. Thus, LUC7L3 potentially plays a modulatory role in this fundamental element of transcription: altered splicing might influence the protein binding of CREB1. Components of 
various cellular processes, such as CUL1, HERC1 and HERC6, were are also affected. CUL1 is a component of the E3 ubiquitin ligase complex and is overexpressed in melanoma, leading to hyperproliferation. ${ }^{[6]}$ The HERC gene family is involved in multiple molecular processes, including cell-cycle regulation, DNA repair and ubiquitination, and is also differentially regulated in psoriatic skin. HERC6 is indicated in E3 conjugation of ISG15. ${ }^{[67]}$ OAS2, indicated in antiviral processes, exhibited marked gene expression upregulation as well as differential exon usage. Several genes with relatively sparse functional characterisation available in the current literature presented markedly altered exon usage. These include NBEAL1, AUH, with RNA binding and hydratase activities, and the HERC2 paralog RCC1. ${ }^{[68-70]}$

Differential exon usage for long non-coding RNAs has been detected using RNA-Seq. ${ }^{[46]}$ We have also detected IncRNAs with differential exon usage, most notably TINCR and NEAT1. The role of NEAT1 is relatively well studied in tumorigenesis: its overexpression has been verified in lung, oesophagus, colorectal and hepatocellular carcinoma. ${ }^{[71]}$ NEAT1 might also be involved in psoriasis, as keratinocyte hyperproliferation is an elementary step in the pathogenesis. The widespread functionality of TINCR IncRNA in keratinocyte maturation has been recently described: whereas another non-coding transcript, ANCR, is needed for the maintenance of keratinocyte precursors, TINCR helps terminal differentiation. In undifferentiated keratinocytes, TINCR is regarded as a low abundance transcript, whereas in differentiated keratinocytes, TINCR exhibited elevated expression. ${ }^{[72,73]}$ Accordingly, we have also shown that TINCR is expressed at low levels in HPV-immortalised cells. Altered splicing patterns might affect TINCR binding capacity through the inclusion of one of its several "TINCR box" motifs.

In our present RNA-Seq experiment, we demonstrated that the LUC7L3 and SFRS18 splicing factors contribute to the regulation of several well-known psoriasis-associated pathways, including the IFN signalling pathway, antiviral immunity and ubiquitination. Regulatory roles of these SR-rich splicing factors have also been verified for fibronectin mRNA maturation. These results, together with our results for long non-coding RNA expression and exon usage changes, might open new insights into molecular disturbances in early psoriasis development caused by altered mRNA maturation.

\section{ACKNOWLEDGEMENT}

The work was supported by OTKA grants $5 \mathrm{~K} 321$ and K105985, and by GINOP-2.3.2-15-2016-00015 and GINOP-2.2.1-15-2016-00007 research grants.

\section{CONFLICT OF INTEREST}

The authors have declared no conflicting interests.

\section{AUTHOR CONTRIBUTION}

ESz performed the experiments and wrote the manuscript, $\mathrm{PO}$ performed bioinformatical analysis and wrote the manuscript, $\mathrm{KSz}$ conceived the study design, FP, ZsB-Cs and LK critically reviewed the manuscript and MSz conceived the study design and critically reviewed the manuscript. All authors have read and approved the final manuscript.

\section{ORCID}

Eszter Szlavicz (iD http://orcid.org/0000-0002-1083-0994

\section{REFERENCES}

[1] F. O. Nestle, D. H. Kaplan, J. Barker, N. Engl, J. Med. 2009, 361, 496.

[2] D. Roberson, A. M. Bowcock, Trends Genet. 2010, 26, 415.

[3] P. Di Meglio, F. Villanova, F. O. Nestle, Cold Spring Harb. Perspect Med. 2014, 4, 8. pii: a015354.

[4] R. Lande, J. Gregorio, V. Facchinetti, B. Chatterjee, Y. H. Wang, B. Homey, W. Cao, Y. H. Wang, B. Su, F. O. Nestle, T. Zal, I. Mellman, J. M. Schröder, Y. J. Liu, M. Gilliet, Nature 2007, 449, 564.

[5] D. Ganguly, G. Chamilos, R. Lande, J. Gregorio, S. Meller, V. Facchinetti, B. Homey, F. J. Barrat, T. Zal, M. Gilliet, J. Exp. Med. 2009, 206, 1983.

[6] A. Farkas, L. Kemeny, Br. J. Dermatol. 2011, 165, 247.

[7] M. A. Lowes, M. Suárez-Fariñas, J. G. Krueger, Annu. Rev. Immunol. 2014, 32, 227.

[8] M. Furue, T. Kadono, Inflamm. Res. 2017, 66, 833.

[9] J. E. Greb, A. M. Goldminz, J. T. Elder, M. G. Lebwohl, D. D. Gladman, J. J. Wu, N. N. Mehta, A. Y. Finlay, A. B. Gottlieb, Nat. Rev. Dis. Primers. 2016, 2, 16082.

[10] K. Otkjaer, K. Kragballe, A. T. Funding, J. T. Clausen, P. L. Noerby, T. Steiniche, L. Iversen, Br. J. Dermatol. 2005, 153, 911.

[11] S. Kunz, K. Wolk, E. Witte, K. Witte, W. D. Doecke, H. D. Volk, W. Sterry, K. Asadullah, R. Sabat, Exp. Dermatol. 2006, 15, 991.

[12] K. Wolk, E. Witte, E. Wallace, W. D. Döcke, S. Kunz, K. Asadullah, H. D. Volk, W. Sterry, R. Sabat, Eur. J. Immunol. 2006, 36, 1309.

[13] J. E. Gudjonsson, J. Ding, X. Li, T. Tejasvi, Z. S. Qin, D. Ghosh, A. Aphale, D. L. Gumucio, J. J. Voorhees, G. R. Abecasis, J. T. Elder, J. Invest. Dermatol. 2009, 129, 2795.

[14] J. E. Gudjonsson, A. Johnston, S. W. Stoll, M. B. Riblett, X. Xing, J. J. Kochkodan, J. Ding, R. P. Nair, A. Aphale, J. J. Voorhees, J. T. Elder, J. Invest. Dermatol. 2010, 130, 1849.

[15] M. Stahle, Exp. Dermatol. 2015, 3, 181.

[16] E. Galimova, R. Rätsep, T. Traks, K. Kingo, V. Escott-Price, S. Koks, Br. J. Dermatol. 2017, 6, 1577.

[17] M. Keermann, S. Koks, E. Reimann, E. Prans, K. Abram, K. Kingo, BMC Genom. 2015, 16, 322.

[18] M. Keermann, S. Koks, E. Reimann, K. Abram, T. Erm, H. Silm, K. Kingo, J. Dermatol. Sci. 2015, 2, 150.

[19] W. Wang, X. Yu, C. Wu, H. Jin, Int. J. Med. Sci. 2017, 10, 1002.

[20] E. C. Baechler, F. M. Batliwalla, A. M. Reed, E. J. Peterson, P. M. Gaffney, K. L. Moser, P. K. Gregersen, T. W. Behrens, Immunol. Rev. 2006, 210, 120.

[21] M. Romanowska, N. Yacoub, H. Seidel, S. Donandt, H. Gerken, S. Phillip, N. Haritonova, M. Artuc, S. Schweiger, W. Sterry, J. Foerster, J. Invest. Dermatol. 2008, 128, 110

[22] M. Blumenberg, Curr. Genomics 2012, 13, 363.

[23] K. Szabo, Z. Bata-Csorgo, A. Dallos, A. Bebes, L. Francziszti, A. Dobozy, L. Kemeny, M. Szell, Acta Derm. Venereol. 2014, 94, 380.

[24] Z. Bata-Csorgo, C. Hammerberg, J. J. Voorhees, K. D. Cooper, J. Clin. Invest. 1995, 95, 317.

[25] F. Pagani, F. E. Baralle, Mol. Diagn. 2010, 155, 155.

[26] A. J. Ward, T. A. Cooper, J. Pathol. 2011, 220, 152.

[27] K. M. Ting, D. Rothaupt, T. S. McCormick, C. Hammerberg, G. Chen, A. C. Gilliam, S. Stevens, L. Culp, K. D. Cooper, J. Invest. Dermatol. $2000,114,706$. 
[28] M. Szell, Z. Bata-Csorgo, A. Koreck, A. Pivarcsi, H. Polyanka, C. Szeg, M. Gaal, A. Dobozy, L. Kemeny, J. Invest. Dermatol. 2004, 123, 537.

[29] J. P. McFadden, D. A. Basketter, R. J. Dearman, I. R. Kimber, Clin. Dermatol. 2011, 29, 265.

[30] A. R. Kornblihtt, C. G. Pesce, C. R. Alonso, P. Cramer, A. Srebrow, S. Werbajh, A. F. Muro, FASEB J. 1996, 10, 248.

[31] E. S. White, F. E. Baralle, A. F. Muro, J. Pathol. 2008, 216, 1.

[32] E. S. White, A. F. Muro, IUBMB Life 2011, 63, 538.

[33] J. Xu, D. Mosher, The Extracellular Matrix: An Overview, SpringerVerlag, Berlin, 2011, 41.

[34] E. Szlavicz, K. Szabo, G. Groma, Z. Bata-Csorgo, F. Pagani, L. Kemeny, M. Szell, Mol. Cell. Biochem. 2017, 436, 189.

[35] H. Polyanka, K. Szabo, G. Tax, V. Tubak, E. Kusz, Z. Ujfaludi, I. Boros, Z. Bata-Csorgo, L. Kemeny, M. Szell, J. Invest. Dermatol. 2011, 131(Suppl. 2), S70.

[36] A. Dobin, C. A. Davis, F. Schlesinger, J. Drenkow, C. Zaleski, S. Jha, P. Batut, M. Chaisson, T. R. Gingeras, Bioinformatics 2013, 29, 15.

[37] D. Kim, G. Pertea, C. Trapnell, H. Pimentel, R. Kelley, S. L. Salzberg, Genome Biol. 2013, 14, R36.

[38] C. Trapnell, B. Williams, G. Pertea, A. Mortazavi, G. Kwan, J. van Baren, S. Salzberg, B. Wold, P. Pachter, Nat. Biotechnol. 2010, 5, 511.

[39] S. Anders, P. T. Pyl, W. Huber, Bioinformatics 2015, 31, 166.

[40] S. Anders, A. Reyes, W. Huber, Genome Res. 2012, 22, 2008.

[41] F. Liu, X. Gao, J. Wang, C. Gao, X. Li, X. Li, X. Gong, X. Zeng, J. Mol. Neurosci. 2016, 58, 170.

[42] J. E. Hooper, Hum. Genomics 2014, 8, 3.

[43] D. Quigley, J. Invest. Dermatol. 2014, 134, 1789.

[44] A. Jabbari, M. Suárez-Fariñas, S. Dewell, J. G. Krueger, J. Invest. Dermatol. 2012, 132, 246.

[45] B. Li, L. C. Tsoi, W. R. Swindell, J. E. Gudjonsson, T. Tejasvi, A. Johnston, J. Ding, P. E. Stuart, X. Xing, J. J. Kochkodan, J. J. Voorhees, H. M. Kang, R. P. Nair, G. R. Abecasis, J. T. Elder, J. Invest. Dermatol. 2014, 134, 1828.

[46] L. C. Tsoi, M. K. Iyer, P. E. Stuart, W. R. Swindell, J. E. Gudjonsson, T. Tejasvi, M. K. Sarkar, B. Li, J. Ding, J. J. Voorhees, H. M. Kang, R. P. Nair, A. M. Chinnaiyan, G. R. Abecasis, J. T. Elder, Genome Biol. 2015, 16, 24.

[47] S. Koks, M. Keermann, E. Reimann, E. Prans, K. Abram, H. Silm, G. Koks, K. Kingo, Front. Med. (Lausanne). 2016, 3, 4632.

[48] Y. Nishii, M. Morishima, Y. Kakehi, K. Umehara, N. Kioka, Y. Terano, T. Amachi, K. Ueda, FEBS Lett. 2000, 465, 153.

[49] H. Umehara, Y. Nishii, M. Morishima, Y. Kakehi, N. Kioka, T. Amachi, J. Koizumi, M. Hagiwara, K. Ueda, Biochem. Biophys. Res. Commun. 2003, 301, 324.

[50] K. L. Shipman, P. J. Robinson, B. R. King, R. Smith, R. C. Nicholson, Biochem. Cell Biol. 2006, 84, 9.

[51] Y. Li, M. Ito, S. Sun, T. Chida, K. Nakashima, T. Suzuki, Sci. Rep. 2016 , 6, 36741.

[52] C. L. Lin, S. Leu, M. C. Lu, P. Ouyang, Biochem. Biophys. Res. Commun. 2004, 321, 638.

[53] G. Zimowska, J. Shi, G. Munguba, M. R. Jackson, R. Alpatov, M. N. Simmons, Y. Shi, S. P. Sugrue, Invest. Ophthalmol. Vis. Sci. 2003, 44, 4715.

[54] H. Gytz, M. F. Hansen, S. Skovbjerg, A. C. Kristensen, S. Hørlyck, M. B. Jensen, M. Fredborg, L. D. Markert, N. A. McMillan, E. I. Christensen, P. M. Martensen, Biol. Cell 2017, 109, 94.

[55] K. Szegedi, E. Sonkoly, N. Nagy, I. B. Nemeth, Z. Bata-Csorgo, L. Kemeny, A. Dobozy, M. Szell, Exp. Dermatol. 2010, 19, 269.

[56] A. M. Bowcock, W. Shannon, F. Du, J. Duncan, K. Cao, K. Aftergut, J. Catier, M. A. Fernandez-Vina, A. Menter, Hum. Mol. Genet. 2010, 17, 1793.

[57] K. Wolk, K. Witte, E. Witte, M. Raftery, G. Kokolakis, S. Philipp, G. Schönrich, K. Warszawska, S. Kirsch, S. Prösch, W. Sterry, H. D. Volk, R. Sabat, Sci. Transl. Med. 2009, 5, 204.
[58] R. A. Raposo, R. Gupta, M. Abdel-Mohsen, M. Dimon, M. Debbaneh, W. Jiang, V. A. York, K. S. Leadabrand, G. Brown, M. Malakouti, S. Arron, P. J. Kuebler, J. J. Wu, S. K. Pillai, D. F. Nixon, W. Liao, J. Eur. Acad. Dermatol. Venereol. 2015, 10, 1951.

[59] W. R. Swindell, X. Xing, J. J. Voorhees, J. T. Elder, A. Johnston, J. E. Gudjonsson, Physiol. Genomics 2014, 46, 533.

[60] H. B. Schonthaler, J. Guinea-Viniegra, S. K. Wculek, I. Ruppen, P. Ximénez-Embún, A. Guío-Carrión, R. Navarro, N. Hogg, K. Ashman, E. F. Wagner, Immunity 2013, 39, 1171.

[61] J. C. Lessard, S. Piña-Paz, J. D. Rotty, R. P. Hickerson, R. L. Kaspar, A. Balmain, P. A. Coulombe, Proc. Natl Acad. Sci. USA 2013, 110, 19537.

[62] M. Caputi, G. Casari, S. Guenzi, R. Tagliabue, A. Sidoli, C. A. Melo, F. E. Baralle, Nucleic Acids Res. 1994, 22, 1018.

[63] E. Buratti, A. F. Muro, A. Giombi, D. Gherbassi, A. laconcig, F. E. Baralle, Mol. Cell. Biol. 2004, 24, 1387.

[64] G. Pellegrini, M. De Luca, G. Orecchia, F. Balzac, O. Cremona, P. Savoia, R. Cancedda, P. C. Marchisio, J. Clin. Invest. 1992, 89, 1783.

[65] K. Y. Okamura, M. Watari, E. S. Jerud, D. W. Young, S. T. Ishizaka, J. Rose, J. C. Chow, J. F. Strauss, J. Biol. Chem. 2002, 276, 10229.

[66] L. Chen, T. Liu, Y. Tu, D. Rong, Y. Cao, Oncol. Rep. 2016, 35, 1049.

[67] S. Sánchez-Tena, M. Cubillos-Rojas, T. Schneider, J. L. Rosa, Cell. Mol. Life Sci. 2016, 73, 1955.

[68] J. E. Hixson, G. Jun, L. C. Shimmin, Y. Wang, G. Yu, C. Mao, A. S. Warren, T. D. Howard, R. S. V. Heide, J. Van Eyk, Y. Wang, D. M. Herrington, Sci. Rep. 2017, 7, 4091.

[69] J. Chen, Y. Lu, J. Xu, Y. Huang, H. Cheng, G. Hu, C. Luo, M. Lou, G. Cao, Y. Xie, K. Ying, Mol. Brain Res. 2004, 125, 147.

[70] J. Nakagawa, H. Waldner, S. Meyer-Monard, J. Hofsteenge, P. Jeno, C. Moroni, Proc. Natl Acad. Sci. USA 1995, 92, 2051.

[71] X. Yu, Z. Li, H. Zheng, M. T. Chan, W. K. Wu, Cell Prolif. 2017, 50, e12329.

[72] M. Kretz, Z. Siprashvili, C. Chu, D. E. Webster, A. Zehnder, K. Qu, C. S. Lee, R. J. Flockhart, A. F. Groff, J. Chow, D. Johnston, G. E. Kim, R. C. Spitale, R. A. Flynn, G. X. Zheng, S. Aiyer, A. Raj, J. L. Rinn, H. Y. Chang, P. A. Khavari, Nature 2013, 493, 231.

[73] M. Kretz, RNA Biol. 2013, 10, 1597.

\section{SUPPORTING INFORMATION}

Additional supporting information may be found online in the Supporting Information section at the end of the article.

FIGURE S1 Combined siRNA silencing of LUC7L3 and SFRS18 splicing factors was the most effective for the alteration of EDA domain inclusion of fibronectin during mRNA maturation. The efficacy of silencing was $83.6 \% \pm 4.24$ for LUCL73 and $70.1 \% \pm 1.56$ for SFRS18, in two replicates

FIGURE S2 Volcano plot of differentially expressed genes upon LUC7L3/SFRS18 double silencing. Dashed line indicates $P$-value cut-off $=.001$

How to cite this article: Szlavicz E, Olah P, Szabo K, et al. Analysis of psoriasis-relevant gene expression and exon usage alterations after silencing of SR-rich splicing regulators. Exp Dermatol. 2018;27:656-662. https://doi.org/10.1111/ exd.13530 